The pipettes can be warmed directly in the flame without danger of breaking them, in case the weighed substance solidifies in the bulb (lard, etc).

On account of the small surface of the bulb in the little pipettes, the error in weighing slightly warmed liquids can be neglected for all practical purposes.

The inside capillary tube nust be turned up as much as possible to gain space. The capillary must have a very small aperture to allow dropping and prevent liquid from entering the suction tube. The apparatus can be easily cleaned by drawing benzene or hot soda solution, etc., through it, then alcohol and ether, and drying it in a current of air.

The weighing pipette is made in different sizes with bulbs from five cc. to roo cc., etc., etc., and is sold by E. Greiner, I 46 and 148 William street, New York City.

IAAORATORY OF BREYER \& SCHWEITZER, I59 FRONT ST., NEW YORK CITY.

[CONTRIBUTIONS FROM THE CHEMICAL LABORATORY OF THE U.S DEPARTMENT OF AGRICUITURE, SENT BY H. W. WILEY.-NO. 7.]

\title{
NOTE ON THE USE OF EOSIN FOR COLORING TOMATOES.
}

BY K. P. MCELROY AND W. D. BIGEI.OW.

Received June 22 .

SOME time since, in accordance with the instructions of $\mathrm{Dr}$. $\checkmark$ Wiley, a qualitative examination was made of a sample of tomato color made by a Cincinnati firm and sent to the Department of Agriculture by Mr. H. E. Taylor, of Brooklyn.

The sample was in a small bottle bearing the label, " tomato color." It consisted of a thin red liquid, showing a strong fluorescence when diluted. Treated with hydrochloric acid a flocky orange precipitate was obtained and the liquid after filtration showed no color, even when made alkaline. The precipitate was freely soluble in alkalies with which it reproduced a red liquid resembling the original. It was also freely soluble in ether, giving a pale yellow solution. A portion of the sample was mixed with lime, evaporated to dryness, and burnt till white. A water solution of the resulting mixture of ash and 
lime after acidifying with nitric acid, gave a heavy precipitate with silver nitrate. Another portion of the solution treated with bleaching powder and hydrochloric acid liberated a substance which was taken up by chloroform, imparting to it a strong yellow color. A portion of the original sample was reduced with sodium amalgam and to the resulting nearly colorless liquid a drop or two of dilute permanganate solution added. A liquid having a deep green fluorescence resulted. The fluorescence was so strong that the liquid was nearly opaque. In view of the reactions cited, the substance under examination was pronounced to be an aqueous solution of brom-eosin (tetrabromfluorescein).

Eosin is one of the most extensively used of the so-called anilin colors. The statement has been made that it is sometimes employed in coloring candy, and more rarely, other articles of food. Its use for coloring tomatoes, however, has never heen published to our knowledge. It is well aclapted for this purpose inasmuch as in a very dilute state it possesses a yellow color not unlike that of the liquor which surrounds canned tonatoes. Addition of a single clrop of the solution exanined to the liquid contents of a can of tomatoes was found to hardly change the color at all, but to cause a marked change for the better in appearance.

At the suggestion of Dr. Wiley an effort was made to work out a method by which brom-eosin could be discovered when added to canned tomatoes. The readiest foundation for such a method appeared to be the fact that eosin can be readily ahstracted from acidified aqueous solutions by ether, and that from this ether solution it in turn can be withdrawn by clilute alkali. The solution so obtained has a characteristic fluorescence.

A large tomato was taken, mashed, and water added. The mixture was divided into two parts and to one a drop of the tomato color added. Both portions were then placed in dishes on the water bath and heated for three hours, replacing the evaporated water from time to time. At the expiration of this time the liquid part was strained off from each portion through cotton bags. The volumes obtained in each case measured 
about $150 \mathrm{cc}$. They were acidified with hydrochloric acid, placed in separatory funnels, and shaken with ether. The aqueous portion of the liquid was then drawn off and the ethereal solution washed with water. After separating from this wash water, twenty cc. of dilute solution of caustic soda were placed in each funnel and the shaking repeated. The alkaline liquid in one funnel then showed a strong yellowgreen fluorescence. The color was almost exactly as intense as that produced in a similar amount of the dilute alkali by a drop of the tomato color. This was the quantity used. On once more shaking the ether remaining in the separatory funnel with alkali an aqueous solution was obtained showing a barely perceptible fluorescence. From this it was evident that the first portion of alkali had extracted practically all of the coloring matter. From the other portion of tomato, the one to which no coloring matter had been added, the alkaline liquid obtained had a slight yellow color, but showed no fluorescence.

A can of tomatoes was next procured, opened, the contents strained in a bag, and the resulting liquid divided into two parts. To one portion a drop of the eosin solution was added. Both portions were then acidulated and extracted with ether. The ether extract in both cases assumed a light yellow color. The ethereal solutions were washed with water several times and then shaken with dilute alkali. Both alkaline solutions were dark colored. Neither showed fluorescence. The ether retained some color. This, of course, was not due to eosin, which, as was just shown, is quantitatively extracted from ethereal solution by alkali. The alkaline liquids were acidified and once more extracted, using fresh ether. Nearly all the coloring matter in the acid liquid was extracted by the ether. After washing the ethereal liquids with water several times they were shaken with more alkali. The resulting solution in one case showed a faint and badly-defined fluorescence. The color of the liquid was too dark, however, to permit any certain recognition of the phenomenon. The ether was not wholly decolorized. It was thrown away, and the two aqueous solutions acidified and extracted with fresh ether. The new ethereal solutions after washing with water gave with alkalies a light 
colored solution, which in one case was unmistakably fluorescent. In the other sample no fluorescence whatever was perceptible. It was therefore evident that the presence of eosin could be recognized with certainty in the presence of the natural coloring matter of the tomato even when existing in but small quantity.

Other experinents were mace in which larger quantities of the tomato color were used-two, three, and four drops to $300 \mathrm{cc}$. of tomato juice. In every case recognition was positive. As a rule one or two extractions were sufficient to allow the fluorescence of the eosin to be easily recognized. Trials were made of the fluorescein reaction proposed by Baeyer for the recognition of eosin to see if it offered any advantage, but such was not found to be the case. The test for bron-eosin, of which the sample under examination consisted is sufficiently delicate and characteristic to render further complication unnecessary. If iod-eosin were used by the canner instead of bronl-eosin it might then be necessary to resort to Baeyer's test, for iod-eosin does not fluoresce and the color is not sufficiently distinctive to permit its recognition. Iod-eosin, however, is higher in price and not so weil adapted for une in canned tomatoes, for a slight fluorescence is rather desirable in this case.

To recapitulate, the nlethod we propose for recognizing the presence of brom-eosin in camned tomatoes is to strain off the solid matter and to the juice add hydrochloric acid and extract with ether. The ethereal solution is to be washed and shaken up with dilute solution of caustic soda. Should this solution be strongly colored, it is to be acidified and extracted with ether, the ether shaken up with dilute alkali and the alternate extractions with ether and alkali repeated till the presence or absence of eosin is demonstrated. The natural coloring matter of the tomato is not completely separated from acid solution by ether, nor is it completely abstracted from ether by alkali, so that by repeating the process sufficiently often it is separated to an extent sufficient to permit the recognition of eosin. Eosin is extracted quantitatively in both cases. Should it be desired to apply Baeyer's method in any case in which the presence of iod-eosin may be suspected it can be done by adding to the

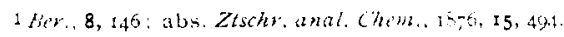


final alkaline liquid some sodium amalgam, gently heating, and finally adding a drop or so of very dilute solution of potassium permanganate. In the presence of either iod-eosin or bromeosin green fluorescence is developed. This test, however, presents no advantage in the case of brom-eosin.

\title{
THE ELECTROLYTIC SEPARATION OF THE METALS OF THE SECOND GROUP.
}

\author{
By SAMUEL C. SCHMUCKER.
}

Received July 8, 1893 .

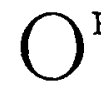

$F$ recent years the determination of metals quantitatively by the methods of electro-chemical analysis has grown into great popularity. The exceedingly accurate results, the simple forms obtained, and the ease with which it is possible to determine the absolute purity of the deposits all combine to make electrolytic methods highly desirable. Hitherto most of the operations have served simply to determine quantitatively the amount of one ingredient present, while comparatively less success has attended the separations of metals from each other. It is true that many valuable separations are known, the results of which have been published in the various chemical journals and in the few books devoted to the subject. But the list of separations of metals in the same group, and of separations of the different groups, is far from complete; and it is to this point that those chemists interested in electrolytic work are now giving their most earnest attention. Here the field seems at present likely best to repay the investigator.

As an example of a gap desirable to fill, I would cite the case of those metals known to analytical chemists as the metals of the second group, viz.: arsenic, antimony, tin, mercury (ic), lead, bismuth, copper, and cadmium. We have no electrolytic method serving for the separation of the first three from any of the later members. An examination of the literature of the subject would disclose to the student of electrolysis that should he encounter, for instance, a mixture containing copper, arsenic, antinony, and tin, he would find himself advised to abandon 